\title{
Effect of Air-excess on Blends of RON70 Partially Premixed Combustion
}

\author{
Shuli Wang1 • P. C. Bakker' ${ }^{1}$ L. M. T. Somers ${ }^{1}$. \\ L. P. H. de Goey ${ }^{1}$
}

Received: 15 March 2015 / Accepted: 1 November 2015 / Published online: 16 November 2015

(C) The Author(s) 2015. This article is published with open access at Springerlink.com

\begin{abstract}
Partially Premixed Combustion (PPC) is a combustion concept that aims to provide combustion with low smoke and NOx emissions and a high thermal efficiency. Extending the ignition delay to enhance premixing, avoiding spray-driven combustion, and controlling temperature at an optimum level through use of suitable dilution levels has been recognized as a key factor to achieve such a concept. Fuels with high auto-ignition resistance do extend ignition delay. In this work three ternary blends of an alcohol (ethanol or n-butanol), n-heptane and iso-octane with a target research octane number (RON) of 70 are studied. RON70 was earlier found to be close to optimal for PPC over a large load range. The objective of this research is to analyze the sensitivity of the combustion parameters to changes in air-excess ratio when using these three blends. The engine was operated at $1250 \mathrm{rpm}$ and 1000 bar injection pressure with a single injection strategy. Results revealed that efficiency was increased from rich to lean combustion, and these three blends show distinct premixed combustion even in lean PPC operation. The premixed fraction of combustion however reduces with the increase of air-excess ratio, which is especially apparent for PRF70 which consists of n-heptane and iso-octane alone.
\end{abstract}

Keywords Partially premixed combustion - Air-excess ratio · Primary reference fuel $\cdot$ IC engines

\section{Introduction}

Diesel engines are widely used in agriculture and transportation sectors due to their high efficiencies which result from their relatively high compression ratios and lack of throttling

Shuli Wang

s.wang@tue.nl

1 Department of Mechanical Engineering, Eindhoven University of Technology, Eindhoven, The Netherlands 
losses. Unfortunately, conventional diesel combustion suffers from high Nitrogen Oxides (NOx) and soot emissions [1,2]. The emission standards for diesel engines become increasingly stringent, which forced the introduction of after-treatment systems for NOx and soot emissions. Advanced combustion strategies combined with the optimal fuels may find an in-cylinder approach to meet these emission standards fully, and avoid the need to use after-treatment or at the very least.

Homogeneous charge compression ignition (HCCI) engines have the advantage of both low NOx emission and high thermal efficiency. In addition, soot emissions decrease in HCCI engines due to leaner mixtures. However, HCCI combustion is kinetically controlled, due to the self-accelerating nature of chemical-kinetic rates as the temperature rises [3], HCCI combustion tends to release heat instantaneously, which can result in unacceptable pressure rise rate (PRR) and even damage the engine.

Partially Premixed Combustion (PPC) can be considered as a hybrid of classical diesel combustion and HCCI combustion. PPC provides the potential of a significant reduction in NOx and soot for diesel engines. Simultaneously, this concept is able to maintain high thermal efficiency. With PPC, a compromise of diesel and HCCI engines can be achieved. For certain temperature and charge stratification, the ignition in PPC engines can be initiated at different times in different spatial locations of the charge, and as such a longer combustion duration and hence a low noise level can be achieved [4] and [5].

The target of PPC is to achieve a separation between the end-of-injection and the startof-combustion. Compared to HCCI, the control of the combustion is re-gained through the injection event and the maximum pressure rise rate is reduced because of an increase in stratification. Kalghatgi et al. [6] and Leermakers [7] showed that PPC engines with highly reactive fuels required a large amount of exhaust gas recirculation (EGR) or low compression ratio to separate the end of the fuel injection and the start-of-combustion, and thus a high octane number fuel was suggested. Due to high volatility and resistance to autoignition, gasoline-like fuels can create the stratified mixture resulting in both high efficiency and low emissions, without compromising on controllability. G. Kalghatgi et al. identified that fuels with a research octane number of 70 are close to optimal for PPC [6].

The correct combination of EGR rate and air-excess ratio controls the in-cylinder temperature. The suitable in-cylinder temperature range, optimal injection strategy and fuels with high resistance to auto-ignition all contribute to minimize the exhaust emissions without a penalty in efficiency.

In principle, a wide variety of bio-fuels can be used for PPC. It is therefore of interest to investigate the behavior of several fuels with a same RON and analyze the sensitivity of the combustion parameters to changes in air-excess ratio for the different blends. Three blends have been selected: n-heptane/ iso-octane mixture (PRF70), n-heptane/ iso-octane/ ethanol mixture (ERF70), and n-heptane/ iso-octane/ n-butanol mixture (BRF70), all with a RON of 70 .

\section{Experimental Apparatus and Methodology}

\subsection{Research engine}

The test-setup used, referred to as CYCLOPS, is based on a $12.6 \mathrm{~L}$ six-cylinder DAF $\mathrm{XE} 355 \mathrm{c}$ engine of which only cylinder 1 is used for testing. The compression ratio of the test cylinder has been altered from the original 17:1 to 15.7:1, to allow for longer mixing. The bore of the engine is $130 \mathrm{~mm}$ and the stroke is $158 \mathrm{~mm}$. The air- and fuel- circuit of 


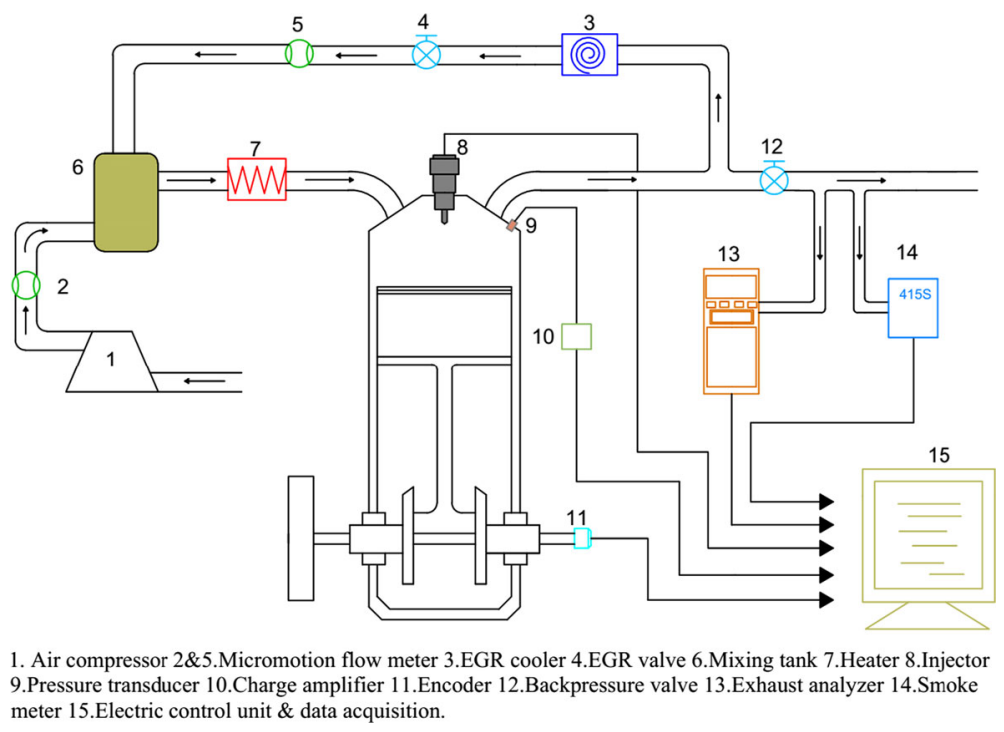

Fig. 1 schematic overview of the test engine

cylinder 1 is separated from the other cylinders. Cylinder 4, 5 and 6 are used to propel the engine, even when the test cylinder is not fired. Figure 1 shows the schematic overview of the test engine. The engine was boosted by using an air compressor. A heater was placed in the manifold to heat up the intake charge to a desired intake temperature. The prototype common rail injector used has 8 holes of $151 \mu \mathrm{m}$ with an umbrella angle of 153 degrees.

The concentration of gaseous emissions, for example, hydrocarbon (HC), carbon monoxide $(\mathrm{CO})$, carbon dioxide $\left(\mathrm{CO}_{2}\right)$ and NOx, are measured using a Horiba Mexa 7100 DEGR exhaust analysis system, which measures $\mathrm{HC}$ by flame ionization method, $\mathrm{CO}$ and $\mathrm{CO}_{2}$ by nondispersive infrared method, and NOx by chemiluminescent method. Smoke emissions (in Filter Smoke Number or FSN units) are monitored using an AVL 415S smoke meter. Fast changing parameters, such as in-cylinder pressure and common rail fuel pressure, are recorded using a SMETEC Combi crank angle resolved system. An in-house TUeDACS data acquisition system is used to measure slow changing parameters, like intake air flow and exhaust gas temperature. These parameters are measured during a period of 40 seconds at a frequency of $20 \mathrm{~Hz}$.

\subsection{Fuels}

A primary reference fuel (PRF) is a blended fuel of n-heptane and iso-octane with octane number rating 0-100. Octane number can affect engine performance range, combustion characteristics and emissions of PPC engines. The higher the octane number, the greater compression the fuel can withstand before igniting. Alcohols, especially ethanol and butanol, have been recognized as suitable fuels for PPC engines due to their high octane numbers. In this study, three fuel blends of RON 70 are tested. Relevant physical properties for the neat compounds can be found in Table 1. Table 2 depicts the properties of the three blended fuels. 
Table 1 The physical properties and heating value for the neat compounds

\begin{tabular}{lllll}
\hline Fuel properties & N-heptane & Iso-octane & Ethanol & n-Butanol \\
\hline Density at $20^{\circ} \mathrm{C}\left(\mathrm{kg} / \mathrm{m}^{3}\right)$ & 679.5 & 692 & 788 & 810 \\
Octane number & & 100 & 109 & 98 \\
Lower heating value $(\mathrm{MJ} / \mathrm{kg})$ & 44.6 & 44.3 & 26.8 & 33.1 \\
Boling point $\left({ }^{\circ} \mathrm{C}\right)$ & 98 & 99.1 & 78 & 118 \\
Heat of evaporation $\left(\mathrm{kJ} / \mathrm{kg}\right.$ from $\left.25^{\circ} \mathrm{C}\right)$ & $316.6^{\mathrm{b}}$ & $300^{\mathrm{a}}$ & $874^{\mathrm{a}}$ & $669^{\mathrm{a}}$ \\
Oxygen $(\mathrm{wt} . \%)$ & & & 34.8 & 21.6 \\
\hline
\end{tabular}

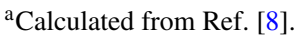

${ }^{\mathrm{b}}$ Ref. [9].

\subsection{Air excess ratio}

In this study, Air excess ratio $(\lambda)$ is calculated from the Brettschneider Equation (1) [10, 11 , which provides the $\lambda$ value based on exhaust emissions and fuel composition.

$$
\lambda=\frac{\left[\mathrm{CO}_{2}\right]+\left[\frac{\mathrm{CO}}{2}\right]+\left[\mathrm{O}_{2}\right]+\left[\frac{\mathrm{NO}}{2}\right]+\left(\left(\frac{\mathrm{H}_{C V}}{4} \times \frac{3.5}{3.5+\frac{[\mathrm{ICO}]}{\left[C O_{2}\right]}}\right)-\frac{O_{C V}}{2}\right) \times\left(\left[\mathrm{CO}_{2}\right]+[\mathrm{CO}]\right)}{\left(1+\frac{H_{C V}}{4}-\frac{O_{C V}}{2}\right) \times\left(\left[\mathrm{CO}_{2}\right]+[\mathrm{CO}]+(\text { Cfactor } \times[\mathrm{HC}])\right)}
$$

In this equation, $[\mathrm{XX}]$ is the gas concentration in volume, $H_{C V}$ is the atomic ratio of hydrogen to carbon in the fuel, $O_{C V}$ is the atomic ratio of oxygen to carbon in the fuel and Cf actor is the number of carbon atoms in each of the hydrocarbons molecules being measured by Horiba Mexa 7100 DEGR. The lambda value calculated by equation (1) is accurate within $1 \%$, independent of the fuel used [11]. The equation above compares all of the oxygen in the numerator, and all of the sources of carbon and hydrogen in the denominator [10,

Table 2 The properties of the three blended fuels

\begin{tabular}{llll}
\hline Blends properties & PRF70 & ERF70 & BRF70 \\
\hline Vol-\% n-Heptane & 30 & 43 & 35 \\
Vol-\% iso-Octane & 70 & 37 & 40 \\
Vol-\% additive & & 20 & 25 \\
Additive & & Ethanol & n-Butanol \\
Oxygen(wt.\%) & 687.0 & 7.77 & 6.11 \\
Density [kg/m ${ }^{3}$ ] & $70 / 70$ & 703.2 & 712.7 \\
RON/MON & & $72.9 / 61$ & $72.9 / 68$ \\
RON test method & & DIN EN ISO 5164 & \\
MON test method & 70 & DIN EN ISO 5163 & \\
Anti-Knock Index (AKI) & 15.1065 & 67 & 70.5 \\
Stoichiometric Air-fuel ratio & 44.47 & 13.7461 & 13.9977 \\
LHV [MJ/kg] & 2.76 & 41.00 & 41.27 \\
LHV of stoichiometric mixture (MJ/kg) & 2.78 & 2.75 \\
\hline
\end{tabular}




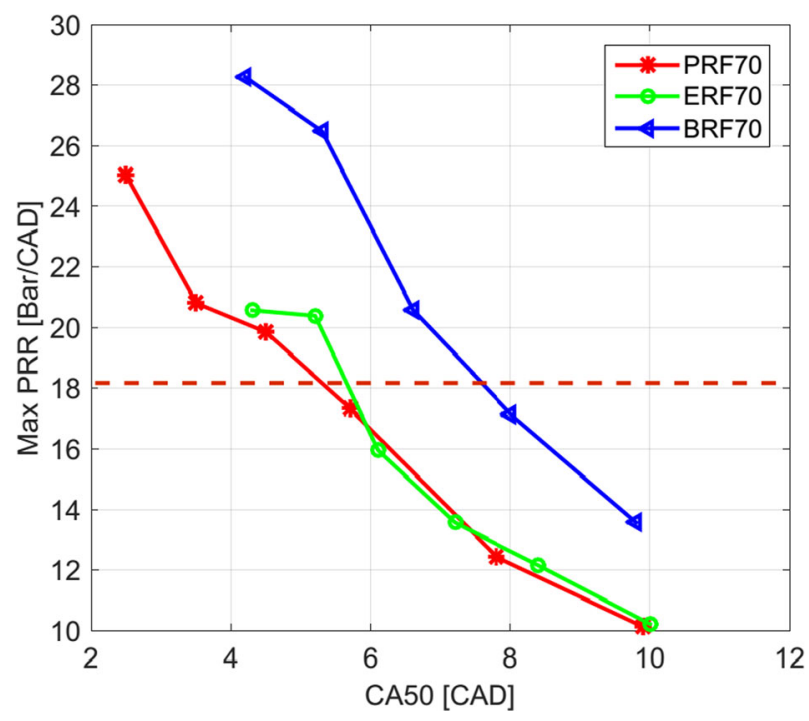

Fig. 2 Maximum PRR vs CA50

11]. Lambda $(\lambda)$ obtained as a dimensionless value to describe different mixtures: $\lambda=1$ stoichiometry, $\lambda>1$ lean combustion, and $\lambda<1$ rich combustion.

\subsection{Definition of related parameters}

The crank angle position where 10 percent of the heat has been released is referred to as CA10. In a similar way, CA50 and CA90 can be defined. CA10 and CA90 are also defined

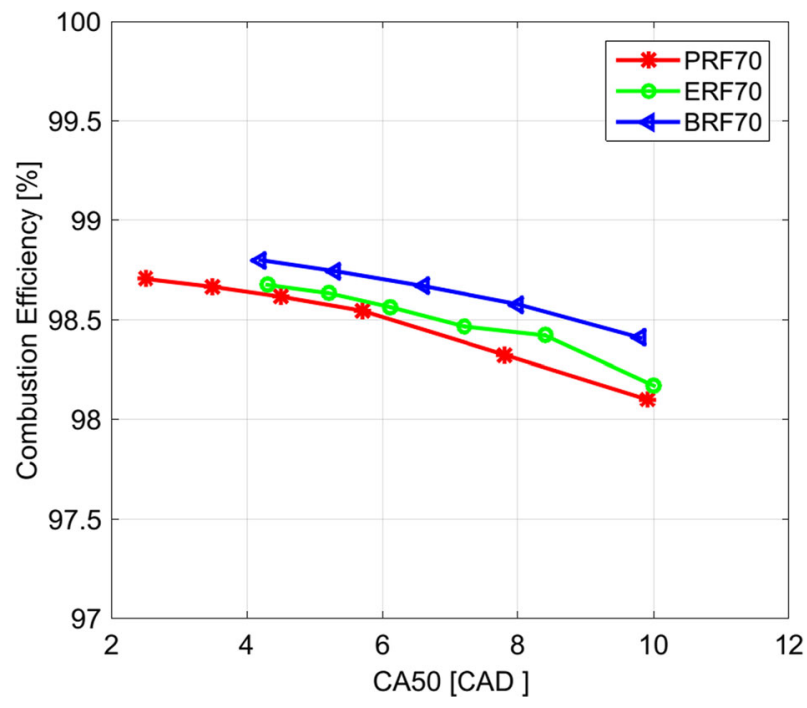

Fig. 3 Combustion efficiency vs CA50 

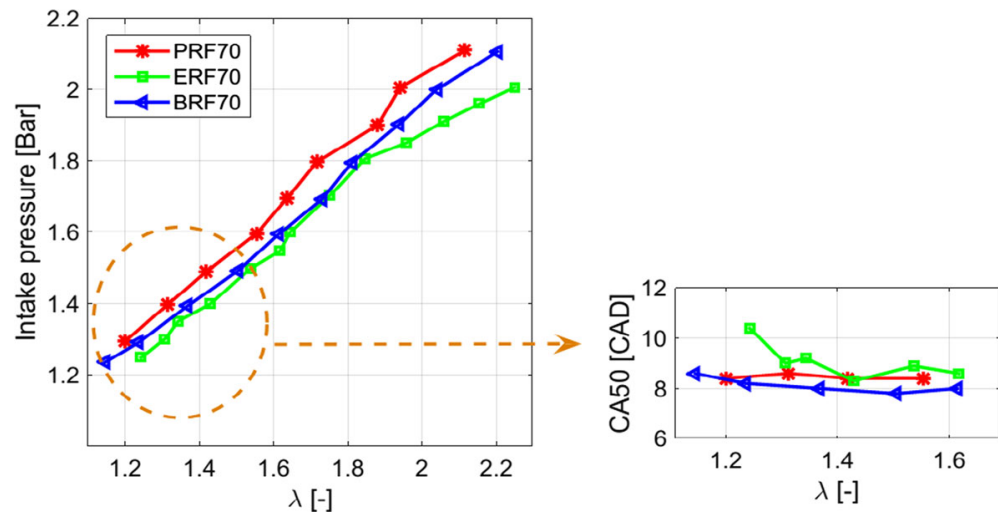

Fig. 4 Changing $\lambda$ through changing intake pressure

as Start of Combustion (SOC) and End of Combustion (EOC), respectively. Analysis of injector current data showed that at $1250 \mathrm{rpm}$ there is a constant delay of 4 CAD between Start of Actuation (SOA) of the injector and Start of Injection (SOI). End of Injection (EOI) can be determined by adding up the injection duration to SOI. Using these definition other combustion parameters are defined:

- $\quad$ Burn Duration $(\mathrm{BD})=\mathrm{EOC}-\mathrm{SOC}(\mathrm{CAD})$

- $\quad$ Ignition Delay (ID) = SOC - SOI (CAD)

- $\quad$ Ignition Dwell (IDw) = SOC - EOI $(\mathrm{CAD})$

In this study, the exhaust gas recirculation (EGR) ratio is experimentally determined based on a comparison between the $\mathrm{CO}_{2}$ mole-concentration in the intake gas and the $\mathrm{CO}_{2}$ moleconcentration in the exhaust gas.

$$
\text { EGR ratio }[\%]=\frac{\left[\mathrm{CO}_{2}, \text { intake }\right]}{\left[\mathrm{CO}_{2}, \text { exhaust }\right]} \times 100
$$

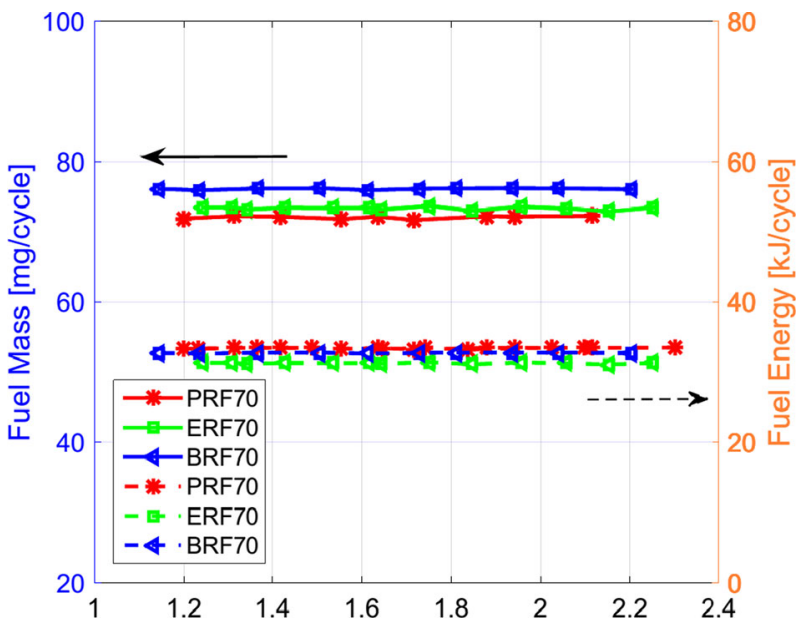

Fig. 5 Fuel mass and fuel energy per cycle as a function of $\lambda$ 
Fig. 6 Cylinder pressures and RoHR data of three blended fuels at various intake pressures

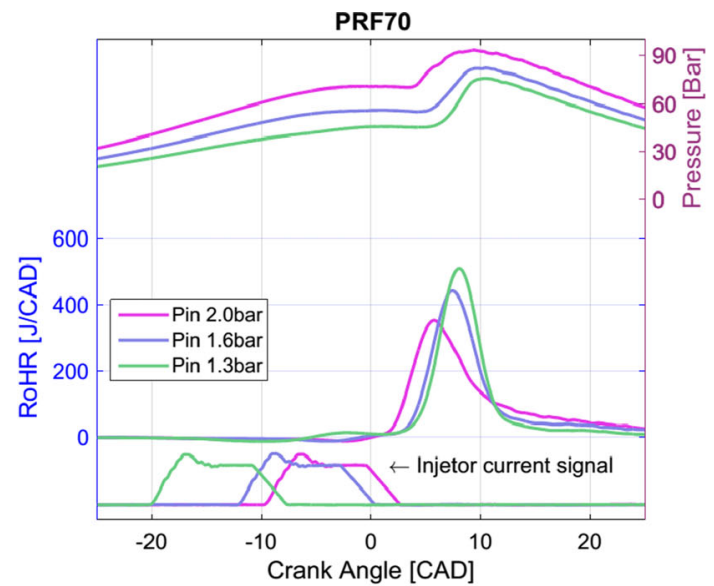

(a) PRF70

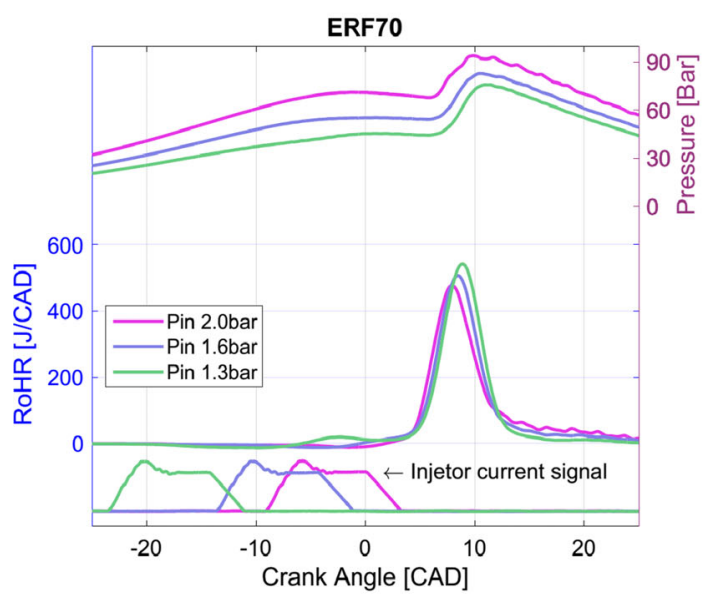

(b) ERF70

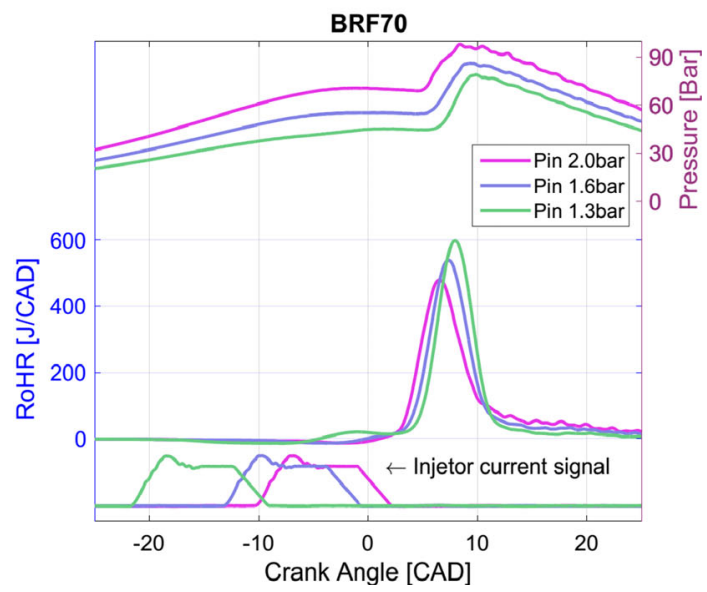

(c) BRF70 


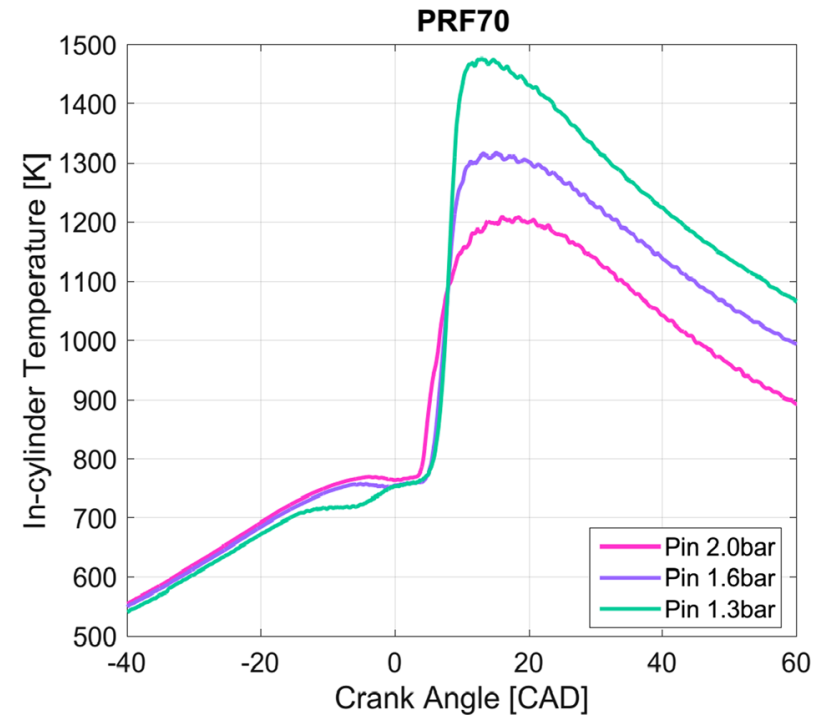

Fig. 7 In-cylinder temperature of PRF70 at various intake pressures

\subsection{Operating conditions and procedure}

In this study, fuel mass is controlled through keeping constant injection pressure at $1000 \mathrm{bar}$ with a single injection and a same injection duration to achieve the aim load 7( \pm 0.3$)$ bar. Experiments are conducted with different air-excess ratios, which are altered by changing air mass through varying the intake pressure. During the measurements, the engine speed is fixed at $1250 \mathrm{rpm}$ and the intake temperature is controlled at $40{ }^{\circ} \mathrm{C}$ with an EGR rate of

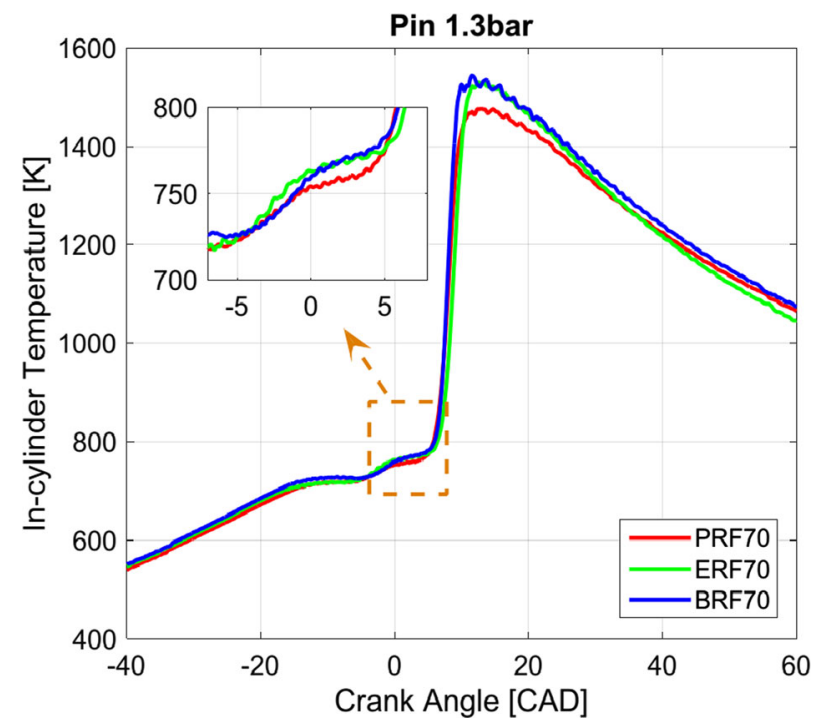

Fig. 8 In-cylinder temperature of the three blended fuels at 1.3 bar intake pressure 


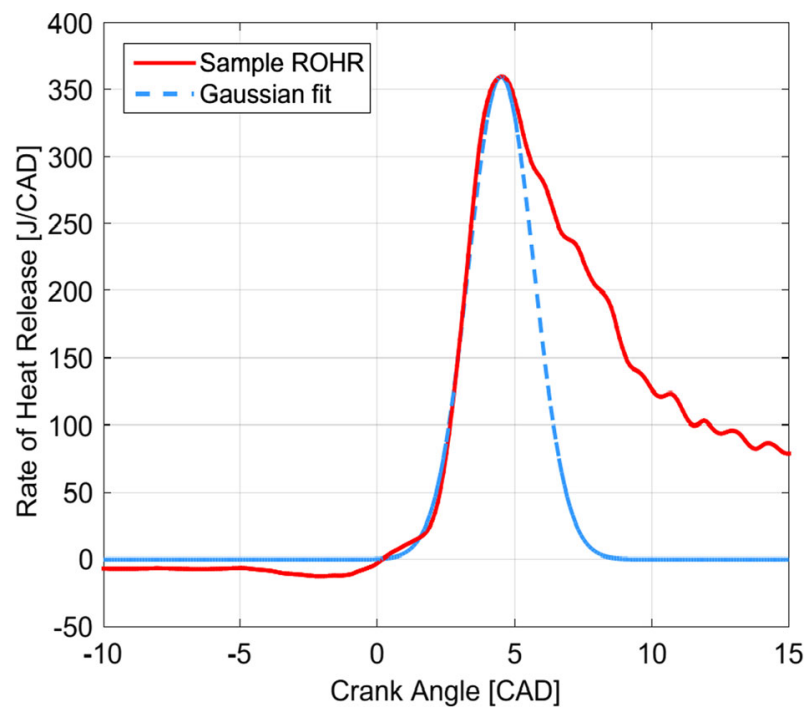

Fig. 9 Gaussian profile and RoHR as a function of crank angle. Gaussian profile is a fit for the premixed combustion

$40 \%$. Pressure rise rates (PRR) should not exceed a certain limit to prevent engine damage and excessive combustion noise. As can be seen from Figs. 2 and 3, the maximum PRR and combustion efficiency increase as CA50 advances. In this study, CA50 has been kept constant at $8 \mathrm{CAD}$ to keep combustion in a safe condition, to maintain a relatively good combustion efficiency, and to investigate the emission characteristics of these blended fuels

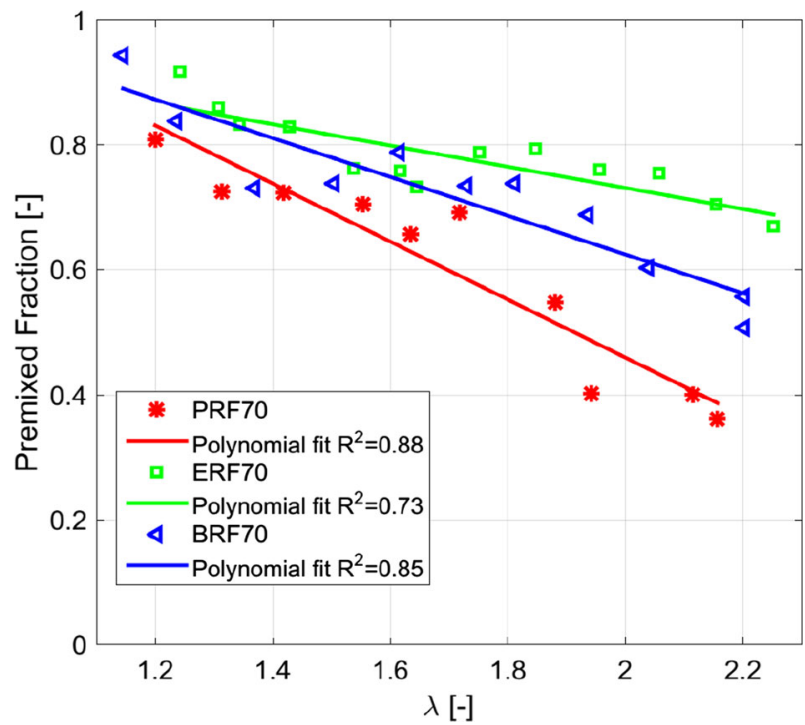

Fig. 10 Premixed fraction and linear polynomial profile as a function of $\lambda$. Linear polynomial profile is a fit for the premixed fraction 
Fig. 11 IDw as a function of $\lambda$

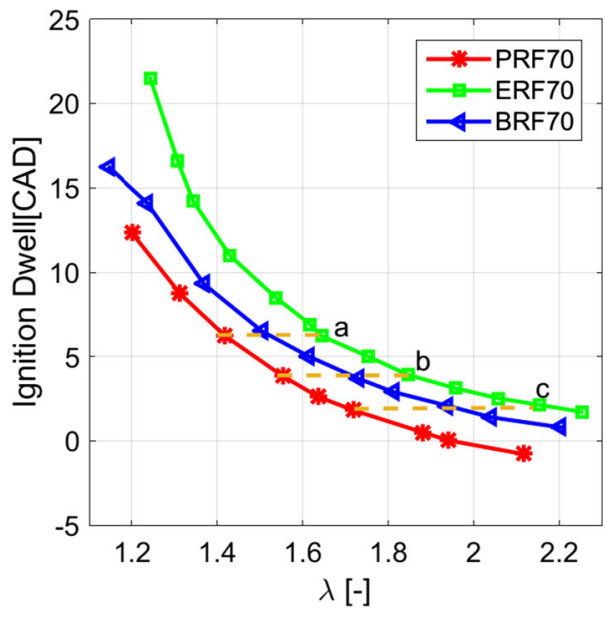

at a same combustion setting for each point. Combustion efficiency is a measure of how efficiently fuel energy is converted into useful energy. When calculating the combustion efficiency, exhaust combustible species like $\mathrm{HC}$ and $\mathrm{CO}$ are considered, while ignoring the effects of other ingredients.

In this study, $\lambda$ varies from 1.2 to 2.3 , the operating points are plotting in Fig. 4 . Compared to PRF70 and BRF70, the combustion phasing (CA50) of ERF70 becomes more and more difficult to control as $\lambda$ moves towards stoichiometric conditions. Due to the higher oxygen content of ERF70, both PRF70 and BRF70 require higher intake pressures to achieve the same $\lambda$ as ERF70.

In this study, injection pressure and injection duration are kept constant for the three blends, while the fuel mass injected into the cylinder each cycle varies a little due to the different densities of the three blends, which is shown in Fig. 5. However, the differences of fuel mass and lower heating value lead to similar input fuel energies every cycle for the three blends (Fig. 5), thus achieving the aim load ( $7 \pm 0.3 \mathrm{bar}$ ).

Fig. $12 \mathrm{BD}$ as a function of $\lambda$

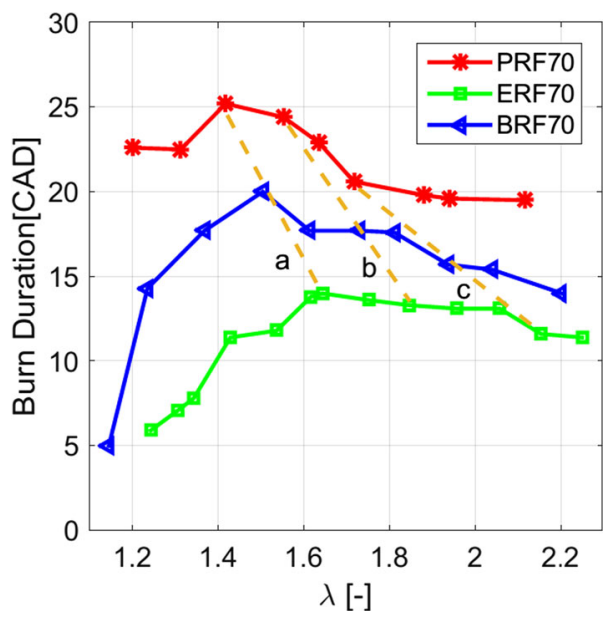




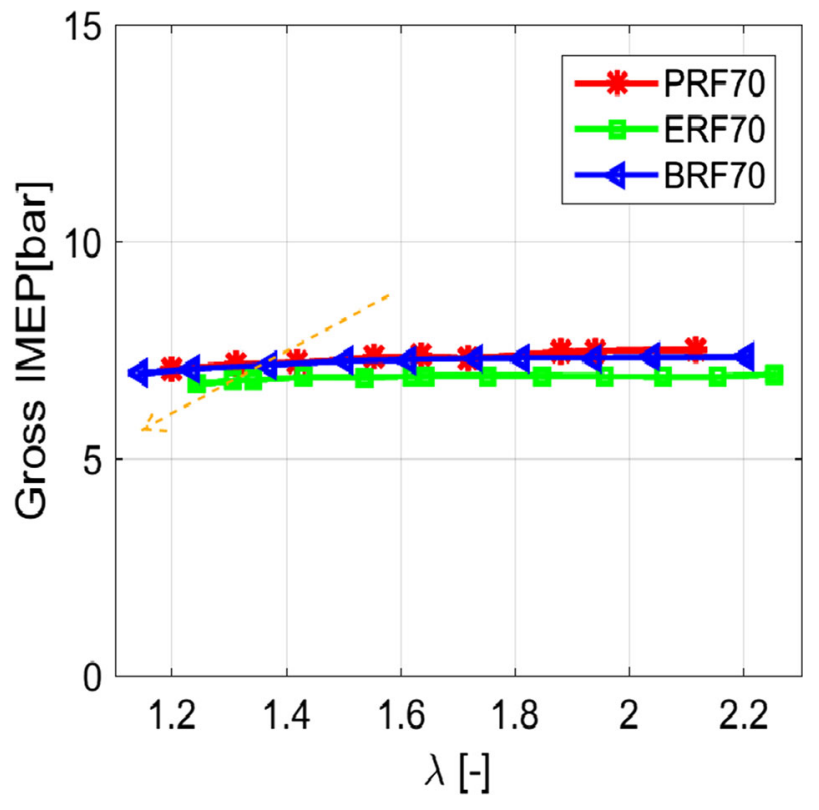

Fig. 13 Gross IMEP as a function of $\lambda$

\section{Results and Discussion}

\subsection{Effects of excess-air on combustion characteristics}

Plots shown in Fig. 6 are the in-cylinder pressure, rate of heat release (RoHR) data and injector current signal for the three blended fuels at various intake pressures respectively. At a higher boost pressure, the cylinder charge becomes leaner as more fresh air mass is forced into the cylinder for the same injected fuel. Moreover, a higher intake pressure provides more oxygen, less wall-wetting, and thus improved fuel-air mixture quality. Consequently, at a higher boost condition, fuels need to be injected later into the cylinder as they ignite more easily. In the relevant temperature regime of this work, the chemical ignition delay times become shorter with decreasing $\lambda$ at near stoichiometric conditions [12]. However, decreased boost pressure and therefore overall lower pressure and density levels respectively lead to longer chemical ignition delay times and deteriorations in mixture formation. Consequently the observation that fuels become more difficult to ignite near stoichiometric conditions is a pressure and density effect rather than a $\lambda$ effect. Therefore, fuels are injected earlier into the cylinder at lower boost pressure conditions to get better fuel-air mixture, which results in the separation between injection event and combustion. In this study low temperature heat release (LTHR) happens only when fuel needs to be injected earlier into the cylinder, which is presented as the small peak on the RoHR curve (Fig. 6). LTHR can increase the temperature and pressure prior to the main hot ignition. Premixed combustion and diffusion combustion can be distinguished by different gradients in RoHR. In premixed combustion, injected fuel has longer time to mix with oxidizer beforehand which results in faster heat release, thus strong gradients in RoHR. However, in diffusion combustion the oxidizer combines with the fuel by diffusion, as a result, the combustion speed 


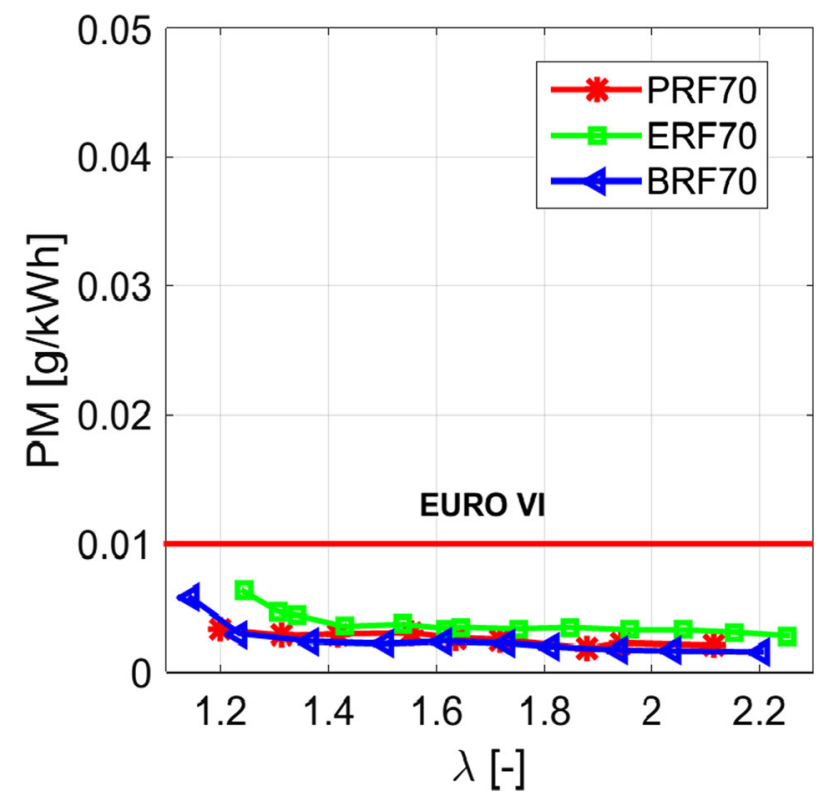

Fig. 14 PM emissions as a function of $\lambda$

is limited by the rate of diffusion. Diffusion combustion tends to combust slower than premixed combustion, thus showing lower gradients. When the absolute intake pressure is set to 2.0 bar, PRF70 start to show two-stage combustion characteristics which are referred to

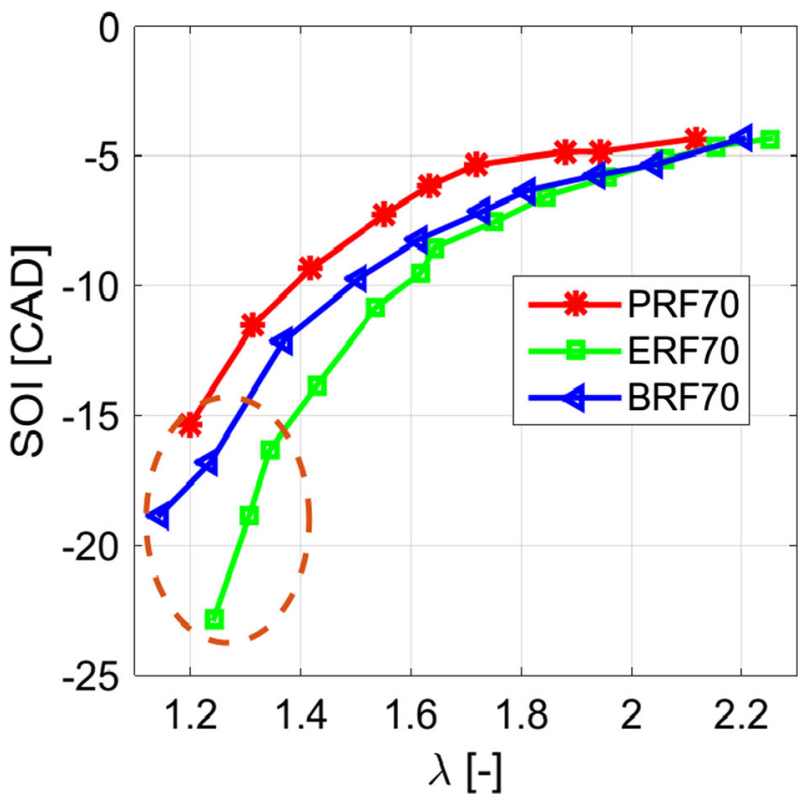

Fig. 15 SOI as a function of $\lambda$ 


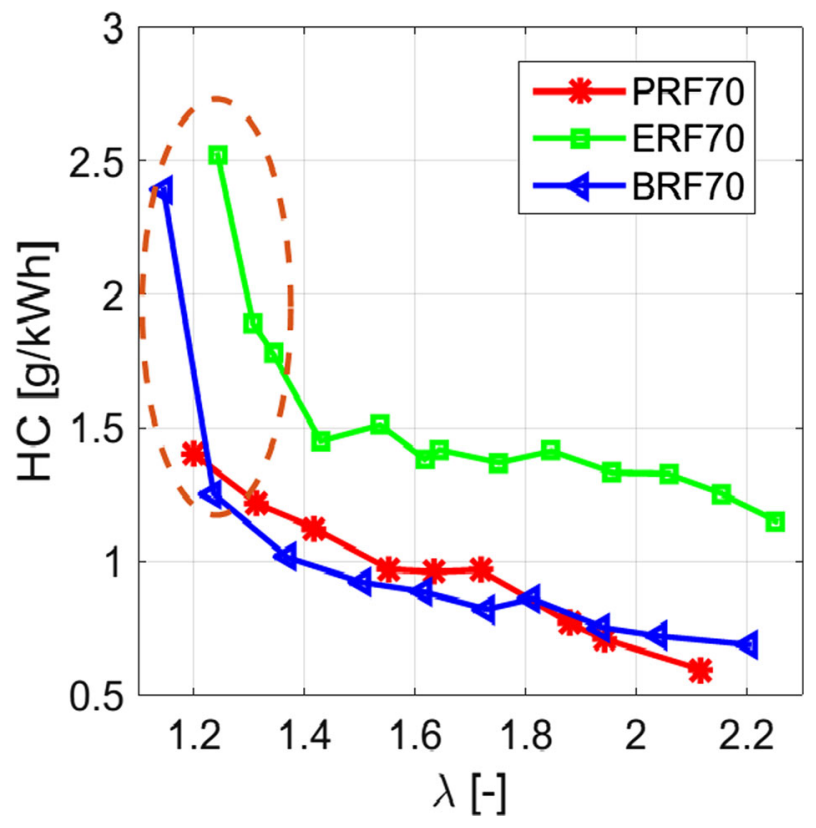

Fig. $16 \mathrm{HC}$ emissions as a function of $\lambda$

as the combination of premixed combustion and diffusion combustion, while ERF70 and BRF70 still show almost pure premixed combustion. When the absolute intake pressure is set to 1.3 bar, ERF70 needs to be injected earlier into the cylinder, compared with PRF70 and BRF70, due to its higher resistance against auto-ignition. With less excess air, the heat release is faster and narrower (less air needs to be heated up) which lead to a higher combustion temperature, as shown in Fig. 7. Moreover, at lower boost conditions (1.3 bar absolute intake pressure), each blended fuel demonstrated a LTHR event followed by the main combustion, or high-temperature heat release (HTHR). According to Szybist [13], "although LTHR mechanisms exist for olefinic and aromatic species, the LTHR under engine conditions can be attributed mainly to n-paraffins". As described in Table 2, ERF70 and BRF70 contain more n-heptane content, which could result in more LTHR. The temperature profiles in Fig. 8 corroborate this as the temperature increase more evident for ERF70 and BRF70 early in the cycle.

Premixed combustion phase is characterized by a rapid combustion that occurs after the low temperature heat release phase and followed by diffusive heat release phase. Premixed combustion phase is controlled by chemical kinetics and the reaction speed depends mainly on the temperature. The premixed-and diffusive- heat release rates are normally not distinctly separated, in this study the degree of premixing is quantified by comparing the integral of the premixed combustion phase with the total heat released. To estimate the 'premixed fraction', a Gaussian profile is fitted to the rising flank of the heat release rate, which is similar to the methodology proposed by Solaka [14]. The Gaussian shape is defined as:

$$
G(x)=h \cdot e^{-\frac{\left(x-x_{0}\right)^{2}}{2 \alpha^{2}}}
$$

where $x_{0}$ is the central position of the peak, $\mathrm{h}$ and $\alpha$ represent the height and width of the Gaussian profile. Figure 9 shows the rate of heat release as a function of crank angle 


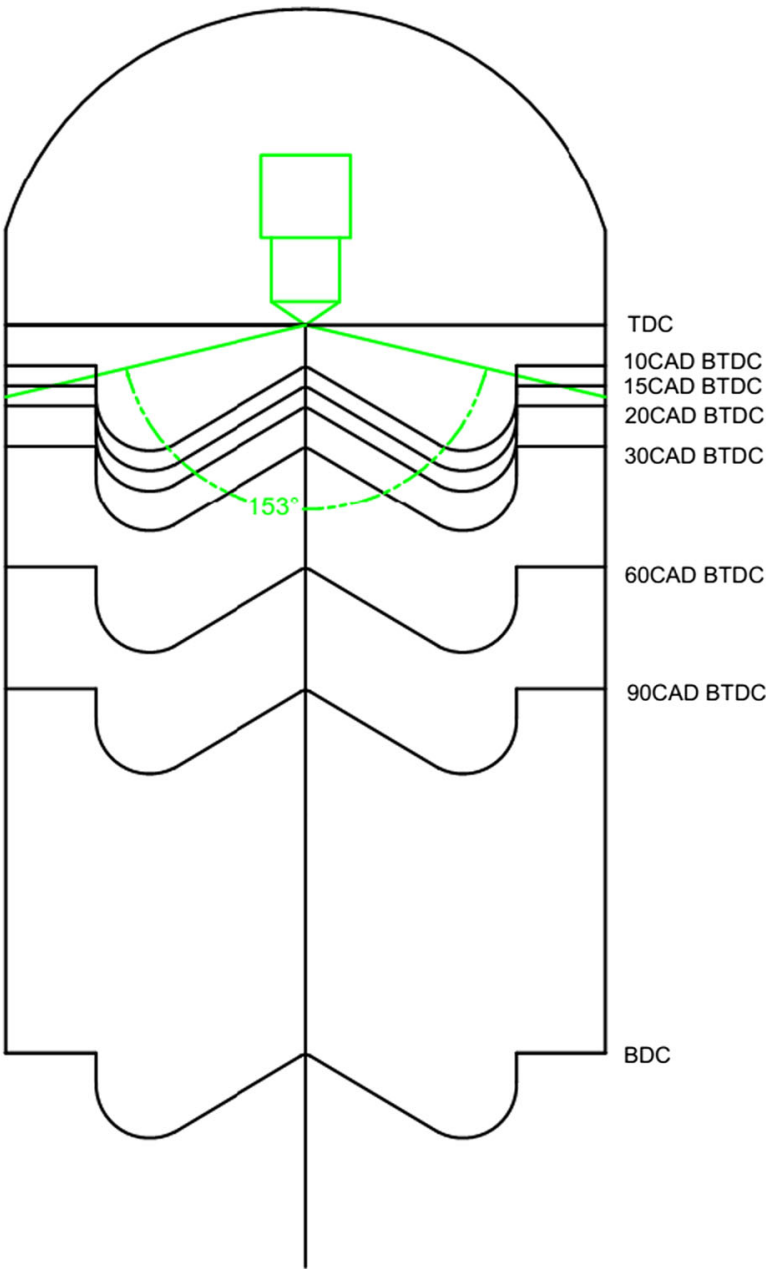

Fig. 17 A sketch of the cylinder, the bowl and the injection

together with the fitted Gaussian profile. The fit follows the premixed heat release closely. The Gaussian profile is a mathematical rather than a physical representation of the premixed reaction phase [15]. However, it can provide a convincing measure of the premixed fractions for all studied cases. The premixed fractions of the three blends decrease with the increase of $\lambda$, which is well illustrated in Fig. 10. Although these three blends have a similar RON around 70 , there is clear difference in the premixed fraction. Lower $\lambda$ needs lower intake pressure which results in longer ignition delay times and thus higher premixed fractions. While higher $\lambda$ requires higher intake pressure, which can improve the mixture formation but shorten the ignition delay, thus leading to lower premixed fractions. Fuel with highest chemical ignition delay (ERF70) allows earlier injection and provides more time for mixture formation, thus presenting the highest premixed fraction and lowest dependency on changing conditions. The observed dependency of the premixed fraction on $\lambda$ is a complex interaction between chemical and physical aspects since in the experimental work not only $\lambda$ but at the meantime also boost conditions are varied. 
Fig. $18 \mathrm{CO}$ emissions as a function of $\lambda$

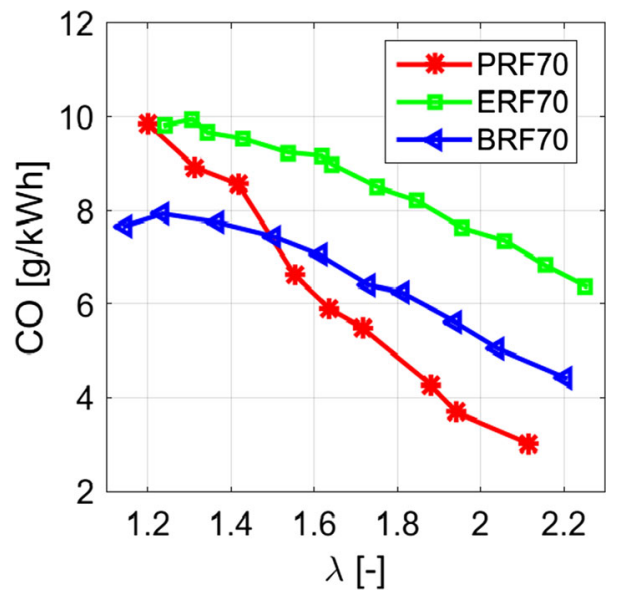

CA50 is near constant for all the measurements by design, but clear trends can be seen with respect to the ignition dwell (Fig. 11) and burn duration (Fig. 12) of the three blended fuels. In Figs. 11 and 12, the dotted line $a$ connects the same ignition dwell points of the three blended fuels under various intake pressures, and the dotted line $b$ and $c$ have the same function. The ignition dwell is used to describe the separation between the fuel injection and combustion events. The target of PPC concept is to separate the end-of- injection and the start-of-combustion, which equals to having a positive ignition dwell, to avoid local rich air-fuel zone and hot zone which will result in high soot and NOx emissions respectivley. Figure 11 shows the ignition dwell decreases when $\lambda$ increases, which is consistent with the change of premixed fraction. Premixed combustion is faster. ERF70 provides the longest ignition dwell times (Fig. 11) and highest premixed fractions (Fig. 10), consequently its heat was released faster than the other two blends. Figure 12 presents how the burn durations change as a function of $\lambda$. Even though these three blended fuels have a similar RON of 70, their ignition properties at PPC conditions are not well determined by RON alone. When $\lambda$ increases, both boost levels and oxygen concentrations increase. Higher boost levels will reduce the premixed time of fuel and air thus exhibiting more diffusion combustion and extending the burn durations, while higher density will accelerate the mixing between oxygen and fuel [16] thus shortening the burn durations. So the burn durations in Fig. 12 is a trade-off between these two factors when varying $\lambda$. With a similar ignition dwell, ERF70 shows the shortest burn period, followed by BRF70, while PRF70 shows the longest burn period. In sum, the difference in burn durations of the three blended fuels is thought to result from different burning rates and thermal stratifications during the combustion event and the burning time for short-chain fuels is shorter than long-chain fuels.

\subsection{Effects of excess-air on emissions}

In this test setup, not just the test cylinder is connected to the engine brake. We cannot use the common practice to calculate these brake specific (i.e. with respect to the power output at the crankshaft). Therefore in this case, the IMEP as calculated from the in-cylinder pressure signal is used. To be able to evaluate the combustion performance also at different intake pressures and varying exhaust back pressures, the gross IMEP (thus excluding the gas exchange stroke) has been used to calculate the indicated fuel consumption and emissions 
Fig. 19 NOx emissions as a function of $\lambda$

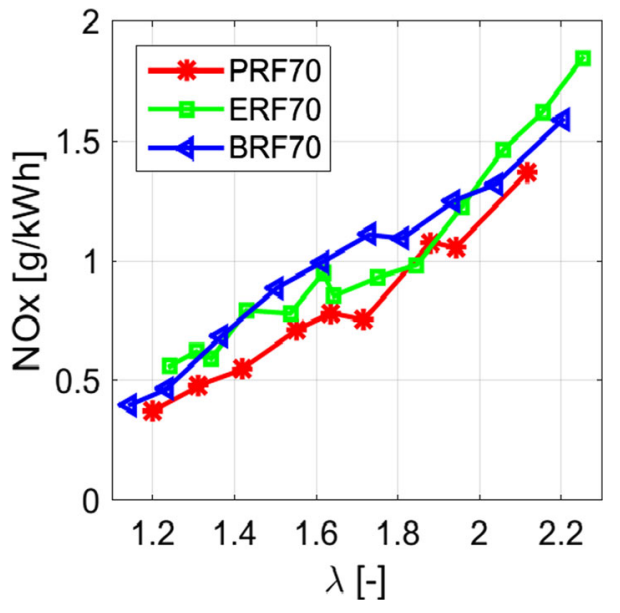

in all results. Gross IMEP decreases gradually as the decrease of $\lambda$, which is shown in Fig. 13. At lower boost conditions, $\mathrm{HC}$ and $\mathrm{CO}$ emissions increase dramatically which are shown in Figs. 16 and 18 respectively, thus resulting in a decrease in combustion efficiency. Moreover, at lower boost conditions the in-cylinder temperature is higher (Fig. 7) and the combustion speed is faster (Fig. 12), both factors cause more heat transferred to the cylinder wall. In sum, gross IMEP goes down as $\lambda$ decreases due to the decreased combustion and thermodynamic efficiencies.

Soot emissions are plotted in Fig. 14 which are all below EURO VI emission standard. Reduced excess-air requires an earlier start-of-injection, because in close-to-stoichiometric operation, fuels are difficult to ignite due to the decreased pressure and density. Figure 15 depicts that SOI advances as $\lambda$ is decreasing and ERF70 has to be injected earlier into the cylinder to get the same CA50 as BRF70 and PRF70. Reduced intake pressure leads to an earlier start of injection, which may cause more fuel go into the squish volume and crevices where are less likely to get fuel fully oxidized, thus producing more unburned $\mathrm{HC}$ emissions. $\mathrm{CO}$ emissions are mainly generated from the partial oxidation of locally rich spots and incomplete combustion due to the lack of sufficient oxygen concentration [17]. $\mathrm{CO}$ emissions are an intermediate product of the oxidation of hydrocarbons in the combustion chamber, the longer ignition delay at close-to-stoichiometric conditions can create more over-lean mixture zones which are also more prone to incomplete combustion.

A sketch of the cylinder, the bowl and the injection is presented in Fig. 17, which is used to show when the spray would hit the wall (assuming the spray instantly traveled along the spray axis). At lower boost conditions, oxygen concentration is low and the three blended fuels provide longer ignition delay times and larger premixed fractions, all these factors can result in shorter combustion durations and more incomplete combustion products ( $\mathrm{HC}$ and CO). Moreover, at lower boost conditions, ERF70 and BRF70 allow injection event start earlier than 17 CAD bTDC (Fig. 15) which can make HC emissions increase dramatically (Fig. 16) due to wall wetting effect (Fig. 17). At conditions of higher boost and more oxygen, the three blended fuels show more diffusion combustion, which can reduce $\mathrm{HC}$ and $\mathrm{CO}$ emissions. In addition, Naber and Siebers [18] reported that injections under higher ambient density resulted in shorter spray penetration distance and greater dispersion angles due to higher air entrainment rate. As a result, a higher intake pressure reduces wall-wetting 
and provides improved mixture quality, thus reducing $\mathrm{HC}$ and $\mathrm{CO}$ emissions (Fig. 18). As can be seen in Fig. 19, NOx emissions increase with increased $\lambda$. When the intake pressure increases, both total dilution level and oxygen concentration increase. NOx levels are expected to decrease with increasing total dilution due to the lower global in-cylinder temperature. Apparently, this is counterbalanced by the higher oxygen concentration.

\section{Conclusions}

The present study explored combustion and emissions characteristics of the three fuel blends under various intake pressure and oxygen concentration levels. From the experimental results aforementioned several conclusions could be drawn:

- Ignition properties at PPC conditions are not well described with the RON alone. Fuel with highest chemical ignition delay (ERF70) allows earlier injection and provides more time for mixture formation, thus leading to highest premixed fraction and lowest dependency on changing conditions.

- Premixed fractions of the three blended fuels decrease with the increase of excess-air. At close to stoichiometric conditions, each blended fuel demonstrated a large premixed fraction ( $>0.8$ ). While at higher boost conditions, mixture formation is improved but the ignition delay time is shortened which results in a decreased premixed fraction.

- At lower boost conditions, the three blended fuels provide longer ignition delay times and larger premixed fractions, which result in shorter combustion durations and more incomplete combustion products ( $\mathrm{HC}$ and $\mathrm{CO}$ ). At higher boost and oxygen concentration conditions, the three blended fuels show more diffusion combustion and combustion duration is extended, which can reduce $\mathrm{HC}$ and $\mathrm{CO}$ emissions but produce more NOx emissions.

Open Access This article is distributed under the terms of the Creative Commons Attribution 4.0 International License (http://creativecommons.org/licenses/by/4.0/), which permits unrestricted use, distribution, and reproduction in any medium, provided you give appropriate credit to the original author(s) and the source, provide a link to the Creative Commons license, and indicate if changes were made.

\section{References}

1. Zheng, Z., Li, C., Liu, H., Zhang, Y., Zhong, X., Yao, M.: Experimental study on diesel conventional and low temperature combustion by fueling four isomers of butanol. Fuel 141, 109-119 (2015)

2. Weall, A., Collings, N.: Investigation into partially premixed combustion in a light-duty multi-cylinder diesel engine fuelled gasoline and diesel with a mixture of. SAE Paper 2007-01-4058

3. Jung, D., Iida, N.: Closed-loop control of HCCI combustion for DME using external EGR and rebreathed EGR to reduce pressure-rise rate with combustion-phasing retard. Appl. Energy 138, 315-330 (2015)

4. Dec, J.E.: Advanced compression-ignition engines-understanding the in-cylinder processes. In: Proceedings of the Combustion Institute, pp. 2727-2742

5. Reitz, R.D.: Directions in internal combustion engine research. Combust. Flame 160, 1-8 (2013)

6. Kalghatgi, G., Risberg, P., Angstrom, H.: Partially premixed auto-Ignition of gasoline to attain low smoke and low NOx at high load in a compression ignition engine and comparison with a diesel fuel, SAE paper 2007-01-0006 
7. Leermakers, C.A.J., Bakker, P.C., Nijssen, B.C.W., Somers, L.M.T., Johansson, B.H.: Low octane fuel composition effects on the load range capability of partially premixed combustion. Fuel 135, 210-222 (2014)

8. Yaws, C.L.: Yaws Handbook of Thermodynamic and Physical Properties of, Chemical Compounds. Knovel (2003)

9. Heptane: [Online]. Available: http://cameochemicals.noaa.gov/chris/HPT.pdf (1999)

10. Brettschneider, J.: Calculation of the air ratio of air-fuel mixtures and the influence of measurement errors on $\lambda$. Bosch Technische Berichte (Technical report) 6, 177-186 (1979)

11. calculation-The Brettschneider Equation, general principles and methods, and its use with alternate fuels, Bridge analyzers, June 2003. [Online]. Available: http://www.bridgeanalyzers.com/EGA/Automotive/ mediaRepos/productDocs/White\%20Paper\%209.pdf

12. Fieweger, K., Blumenthal, R., Adomeit, G.: Self-ignition of S.I. engine model fuels: A shock tube investigation at high pressure. Combust. Flame 109(4), 599-619 (1997). doi:10.1016/S0010-2180(97)00049-7

13. Szybist, J.P., Boehman, A.L., Haworth, D.C., Koga, H.: Premixed ignition behavior of alternative diesel fuel-relevant compounds in a motored engine experiment. Combust. Flame 149(1-2), 112-128 (2007)

14. Solaka, H., Aronsson, U., Tuner, M., Johansson, B.: Investigation of partially premixed combustion characteristics in low load range with regards to fuel octane number in a light-duty diesel engine. SAE paper 2012-01-0684

15. Leermakers, C., Bakker, P., Somers, L., de Goey, L., et al.: Commercial naphtha blends for partially premixed combustion. SAE Int. J. Fuels Lubr., 2013-01-1681

16. Maiboom, A., Tauzia, X., Hétet, J.-F.: Experimental study of various effects of exhaust gas recirculation (EGR) on combustion and emissions of an automotive direct injection diesel engine. Energy 33(1), 22-34 (2008)

17. Ekoto, I.W., Colban, W.F., Miles, P.C., Park, S.W., Foster, D.E., Reitz, R.D., et al.: UHC and CO emissions sources from a light-duty diesel engine undergoing dilution-controlled low-temperature combustion. SAE paper 2009-24-0043

18. Naber, J.D., Siebers, D.L.: Effects of gas density and vaporization on penetration and dispersion of diesel spray. SAE paper 960034 